\title{
Two Different Types of Double-Strand Breaks in Saccharomyces cerevisiae Are Repaired by Similar RAD52- Independent, Nonhomologous Recombination Events
}

\author{
KATE M. KRAMER, ${ }^{1}$ JO ANN BROCK, ${ }^{2}$ KERRY BLOOM, ${ }^{2}$ J. KENT MOORE, ${ }^{1}$ \\ AND JAMES E. HABER ${ }^{1 *}$ \\ Rosenstiel Basic Medical Sciences Research Center and Department of Biology, Brandeis University, \\ Waltham, Massachusetts 02254-9110, ${ }^{1}$ and Department of Biology, University of \\ North Carolina, Chapel Hill, North Carolina 27599-3280
}

Received 18 August 1993/Returned for modification 5 October 1993/Accepted 20 October 1993

\begin{abstract}
In haploid rad52 Saccharomyces cerevisiae strains unable to undergo homologous recombination, a chromosomal double-strand break (DSB) can be repaired by imprecise rejoining of the broken chromosome ends. We have used two different strategies to generate broken chromosomes: (i) a site-specific DSB generated at the MAT locus by $\mathrm{HO}$ endonuclease cutting or (ii) a random DSB generated by mechanical rupture during mitotic segregation of a conditionally dicentric chromosome. Broken chromosomes were repaired by deletions that were highly variable in size, all of which removed more sequences than was required either to prevent subsequent $\mathrm{HO}$ cleavage or to eliminate a functional centromere, respectively. The junction of the deletions frequently occurred where complementary strands from the flanking DNA could anneal to form 1 to 5 bp, although 12\% (4 of 34) of the events appear to have occurred by blunt-end ligation. These types of deletions are very similar to the junctions observed in the repair of DSBs by mammalian cells $(D$. B. Roth and $J$. H. Wilson, Mol. Cell. Biol. 6:4295-4304, 1986). When a high level of $\mathrm{HO}$ endonuclease, expressed in all phases of the cell cycle, was used to create DSBs, we also recovered a large class of very small (2- or 3-bp) insertions in the HO cleavage site. These insertions appear to represent still another mechanism of DSB repair, apparently by annealing and filling in the overhanging $3^{\prime}$ ends of the cleavage site. These types of events have also been well documented for vertebrate cells.
\end{abstract}

Repair of double-strand breaks (DSBs) in Saccharomyces cerevisiae by homologous recombination is very efficient, in both meiotic and mitotic cells $(16,41,46)$. There appear to be two major mechanisms of DSB repair in mitotic cells (14). Gap repair (63) is a conservative mechanism in which a DSB is expanded into a single-stranded or double-stranded gap. Repair from homologous sequences leads to a gene conversion event. An alternative nonconservative pathway is called single-strand annealing (SSA), in which a DSB between direct repeats of homology leads to a deletion and the loss of intervening sequences between the direct repeats (16). Both of these repair mechanisms require extensive homology for efficient recombination $(1,33,59)$.

The $R A D 52$ gene product is required for most mitotic recombination in $S$. cerevisiae, including mating-type switching $(31,66)$, integration of transformed linear DNA (37), and repair of both enzyme-induced and nonspecific DSBs $(4,36,45,50)$. RAD52-independent repair by SSA between direct repeats of 1 to $2 \mathrm{~kb}$ occurs at a much lower efficiency than in $\mathrm{Rad}^{+}$strains $(4 ; 14,43)$; however, DSB repair by SSA in large arrays of tandemly repeated genes such as $r D N A$ and $C U P 1$ is efficient in rad52 strains (38).

Because repair of DSBs by homologous recombination is very efficient in $S$. cerevisiae, a strong selection scheme is needed to look for nonhomologous repair pathways. In three previous studies, illegitimate recombination has been examined using transformation of linear DNA. In one experiment, plasmid DNA was linearized by a cut within lac $Z$ sequences that were not homologous to any chromosomal sequences

${ }^{*}$ Corresponding author. Phone: (617) 736-2462. Fax: (617) 7362405. Electronic mail address: haber@hydra.rose.brandeis.edu.
(29). Most of the rare transformants recovered were headto-head dimer plasmids. The mechanism of end joining appeared to depend on homologous interactions along the length of two molecules of transformed DNA since only head-to-head and no head-to-tail joinings were recovered. In another series of experiments $(53,55)$, DNA fragments that had been cut with BamHI preferentially integrated into chromosomal GATC sites by interaction of the BamHIgenerated GATC ends of the fragment. Finally, linear transformed fragments having homeologous sequences at either end with 52 or $73 \%$ sequence identity were found to recircularize to generate a replicative plasmid. The junction of these recombination events involved short (2 to $21 \mathrm{bp}$ ) regions of identity but also required a general alignment of the homologous sequences so that most of the repair events maintained the open reading frame between the two diverged gene copies (33). Despite the very small degree of sequence identity at the junctions, these events require $R A D 52$ gene function, possibly for the general alignment of homeologous sequences.

In mammalian cells, nonhomologous recombination events are far more common than in $S$. cerevisiae, as illustrated by the fact that in mammalian cells only 1 in 100 transformants involves homologous integration of the transforming DNA $(10,47)$. End joining appears to be the most common pathway of DSB repair in mammalian cells. A variety of both in vivo and in vitro studies of end-joining events arising by nonhomologous DNA interactions in eucaryotic systems has revealed that in many cases short stretches of DNA identity are involved in end-joining events $(25,40,47,64)$, although broken DNA ends can be joined together by simple ligation as well $(49,65)$. 
We have studied repair of DSBs by illegitimate recombination in nontransformed yeast cells in which chromosomal DSBs were generated in vivo. We have compared endjoining events in two systems: (i) a site-specific DSB generated at the $M A T$ locus $\mathrm{HO}$ cut site in a rad52 haploid strain unable to repair the break by homologous recombination and (ii) undefined breaks created between two centromeres of a conditionally dicentric chromosome III during mitosis in a rad52 haploid. Although a simple rejoining of broken ends would not eliminate the lethal condition, further chromosomal breakage could be prevented by the formation of deletions. In both cases, the sizes of deletions were larger than was required either to remove the HO cutting site or to eliminate the function of the conditional centromere. Our results suggest that microhomologies of a few base pairs frequently direct end joining of broken chromosomes, although in some cases we find no homology at the deletion junction. The spectrum of repair events is very similar to that observed in mammalian cells (49), indicating that mechanisms of end joining may be similar in all eucaryotes.

\section{MATERIALS AND METHODS}

Strains. Strain BW330-26A (HO MAT $\alpha$ swi1 rad52 met13 his5 ade2 mal2) was constructed as described previously (67). Dicentric strain J178-\#7-20 (MATa ade1 met14 ura3-52 leu2-3,112 his3 his4::GALCEN3::URA3 rad52::LEU2) was constructed as described previously $(4,21)$. Monocentric strain J178-20 (ho MATa ade1 met14 ura3-52 leu2-3,112 his3 $\Delta$ rad52) was constructed as described previously $(4,21)$. The URA3-GAL::HO plasmid pJH132 was transformed into strain J178-20 by the lithium acetate method described by Schiestl and Gietz (54) to create strain J178-20T. Growth media have been previously described by Rudin and Haber (50) and Sherman et al. (58).

Generating deletions. (i) BW330-26A derivatives. In cells with $H O$ activity but which are unable to complete $M A T$ switching in the rad52 background, a double-strand cut will be lethal unless the cut site becomes deleted or mutated (66). Surviving cells carrying deletions that remove part of the $M A T \alpha 1$ gene are recognized as sterile, while survivors that have parts of both $M A T \alpha 1$ and $M A T \alpha 2$ deleted are a mating (67).

(ii) J178-\#7-20 derivatives. Deletions that removed all or part of a centromere were recovered by growing cells carrying a galactose-suppressed conditional centromere as well as a normal centromere on chromosome III on glucose medium and analyzing survivors as described elsewhere (4).

(iii) J178-20T derivatives. J178-20 cells were transformed with plasmid pJH132, in which the $H O$ gene is carried on a single-copy plasmid under control of the GAL10 promoter $(4,8,24,68)$. When these cells are grown on glucose, there is little or no HO cutting, while growth on galactose induces HO production, and cutting at $M A T$ is very efficient. Strains were grown in nonfermentable yeast extract-peptone (YP)lactate medium overnight and plated in serial dilutions onto galactose-containing synthetic medium lacking uracil to isolate mutants at the HO cut site and onto glucose-containing synthetic medium lacking uracil to determine survival rates. Colonies surviving galactose growth were picked as deletion derivative candidates. They were classified genetically as $M A T$ a or matal by mating to a MAT $\alpha$ tester strain. A $M A T \mathrm{a} / M A T \alpha$ diploid has a nonmating phenotype, indicating a functional $M A T$ al gene product. matal $/ M A T \alpha$ diploids have an $\alpha$-mating phenotype because they lack the $M A T \mathbf{a} 1$ gene product (for a review, see references 17 and 20). Both types of survivors were further analyzed by Southern mapping and sequence analysis.

PCR and sequencing. Strains were grown overnight in $5 \mathrm{ml}$ of rich yeast extract-peptone-dextrose (YEPD) medium, and DNA was prepared by the sodium dodecyl sulfate (SDS)potassium acetate method (58). An -5-ng amount of genomic DNA was used in each PCR amplification reaction $(2,51)$ with a Techne Programmable Dri-Block PHC-1 temperature cycling machine. The oligonucleotides used were synthesized with a Cyclone V1.05 synthesizer by using phosphoramidite chemistry. Two pairs of primers used for DNA amplifications around the HO-cut site were synthesized on the basis of known sequences at $M A T$. Primers for amplification of the $C E N 3$ deletions were synthesized on the basis of known sequences flanking the BamHI GAL1::CEN3 fragment.

MAT primers HD (distal to the HO cut site) and HP (proximal to the HO cut site) were as follows: 735 (HD), 5'-ATGTGAACCGCATGGGCAGT-3'; BRLA (HD), 5'AATATTAGTGGGTTAATACA-3'; BRL6 (HP), 5'-GG TAAATTACAGCAAATAGA-3'; and \#867 (HP), 5'-CTG GTAACTTAGGTAAATTACAGC-3' . CEN3 primers were as follows: 3050 (left of $G A L 1:: C E N 3$ ), $5^{\prime}$-TCGACTACGC GATCATGGCG-3'; 3051 (right of GAL1::CEN3), 5'-CAC GATGCGTCCGGCGTAGA-3'.

The parameters of the amplification cycle were as follows: denaturation at $95^{\circ} \mathrm{C}$ for $1.5 \mathrm{~min}$, annealing at $48^{\circ} \mathrm{C}$ for $1 \mathrm{~min}$, and polymerization at $72^{\circ} \mathrm{C}$ for $0.1 \mathrm{~min}$ per $100 \mathrm{bp}$. PCR was run for 30 cycles with a final polymerization step at $72^{\circ} \mathrm{C}$ for $7 \mathrm{~min}$. The enzyme used for DNA amplification was either Pyrostase (Molecular Genetic Resources, Inc.) or Deep Vent $_{R}$ Polymerase (New England Biolabs). Primers were removed from the PCR product by treatment with Prep-agene (Bio-Rad). The approximate sizes of the deletions were estimated by gel electrophoresis of ethidium-stained PCR product, and an appropriate sequencing primer was used for sequencing with an fmol sequencing kit (Promega). An -50-ng amount of PCR-amplified DNA was used in each sequencing reaction.

\section{RESULTS}

Deletions at the $\mathrm{HO}$ cut site. A strong selection process was designed to look for events in which a DSB had healed by illegitimate recombination. Haploid strain BW330-26A has a HO MAT $\alpha$ rad52 swil-1 genotype. In normal cells, the HO endonuclease makes a specific cut at the $M A T$ locus to initiate the mating-type switch (for a review, see reference 17). In $\mathrm{BW} 330-26 \mathrm{~A}$, this is a lethal event because $R A D 52$ is essential for completion of the mating-type switch $(31,66)$. However, since $H O$ expression is low because of the swil-1 mutation $(18,35,66)$, the DSB occurs in only a small proportion of the cell population, allowing the strain to be propagated. Cells in which an HO cut has occurred have a transient a-like mating type because of disruption of the $M A T \alpha 1$ and $M A T \alpha 2$ genes. Thus, the mating type of a population of cells is $\alpha>\mathbf{a}$. A few $M A T \alpha$ cells attempting to switch mating type survived the DSB by deleting sequences around the $\mathrm{HO}$ cut site and becoming resistant to subsequent HO cleavage. Nine such subclones were recovered, eight of which had deletions that removed part or all of the MAT $\alpha 1$ sequences in which the HO cut site is embedded. Because cells with the genotype matal MATa2 are sterile, these derivatives had a nonmating phenotype. The remaining subclone with a stable a-like phenotype was mat 1 l mato2, having a deletion that removed $M A T \alpha l$ sequences and part 
A

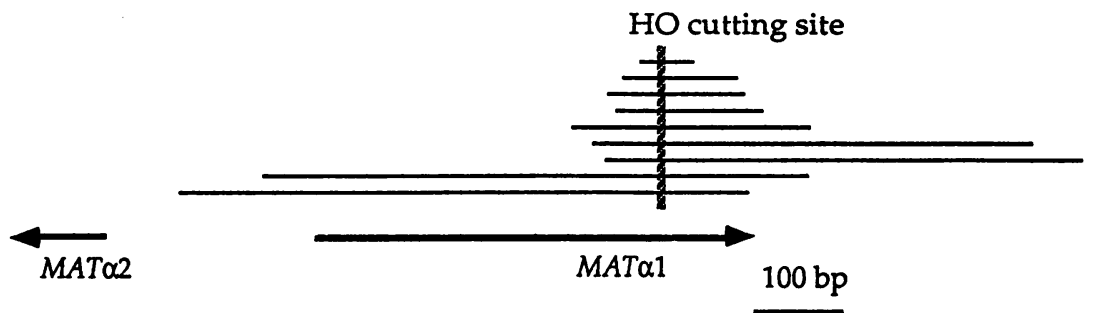

B

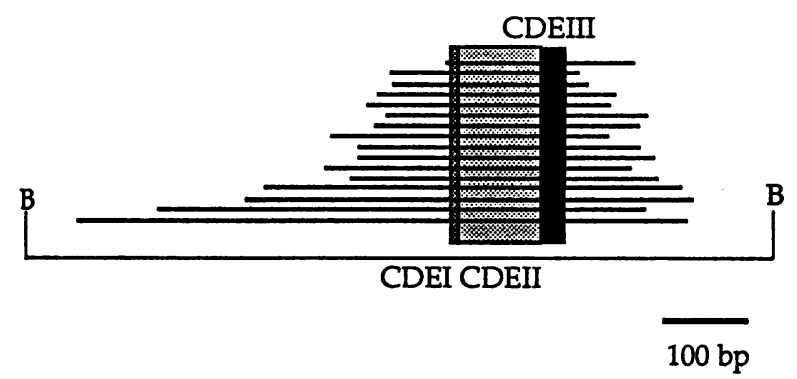

C

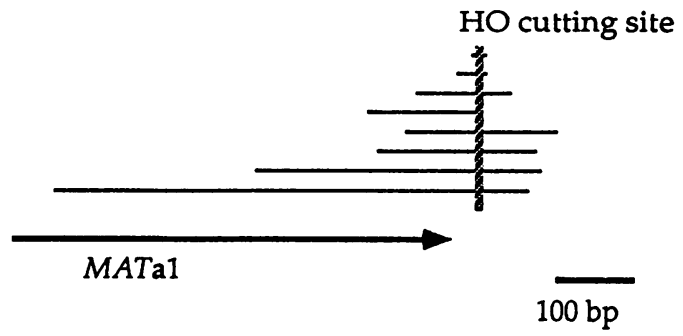

FIG. 1. Sizes and positions of nonhomologous deletions. Deletion events from each strain are shown in their chromosomal contexts. Each horizontal line represents sequences deleted relative to the relevant chromosomal sequences shown at the bottom of each deletion group. (A) Deletions recovered from $H O$ swil-1 rad52 strain BW330-26A. Sequences deleted are shown relative to the HO cut site on chromosome III. $M A T \alpha 1$ and MAT 22 open reading frames are indicated by arrows. (B) Deletions recovered from GAL1::CEN3 rad52 dicentric strain J178-\#7-20 after transfer to glucose medium. Sequences deleted are shown relative to CEN elements CDEI to CDEIII, indicated as shaded bars. (C) Deletions recovered from MATa GAL1::HO rad52 monocentric strain J178-20T. Sequences deleted are shown relative to the HO cut site and the MATal transcript. The deletions shown do not include a large class of very small (1- to 3-bp) insertions and deletions at the HO cutting site (see text).

of the promoter shared by $M A T \alpha 1$ and $M A T \alpha 2$ (67) (Fig. 1A). Deletions around the HO cut site occurred at a frequency of $1 \%$ among $H O$ rad52 swil-1 MAT $\alpha$ cells (67). The actual frequency of deletions is likely to be higher, since the $H O$ gene is expressed only in a small proportion of cells with this genotype.

Deletion junctions were sequenced by amplifying the relevant DNA sequences by using PCR and directly sequencing the PCR product. The sizes of the deletions varied between 62 and $698 \mathrm{bp}$, with a mean size of $282 \mathrm{bp}$, in good agreement with a previously published Southern analysis of these events (67). The locations of the deletions relative to the HO cut site are shown in Fig. 1A. We note that the deletions are much larger than necessary to relieve lethality, given that a single nucleotide deletion at the $\mathrm{HO}$ cut site eliminates cutting by the $\mathrm{HO}$ endonuclease (67; see below).

To understand how these deletions arose, we looked for the presence of nucleotide homologies at the junction site that could effect joining of flanking DNA by annealing of complementary single strands. For example, in deletion strain BW-D2, there is a five-nucleotide junctional homology of GAAGA; Fig. 2A illustrates how strand annealing might have played a role in this particular deletion event. The convention that we have used to represent sequences at the deletion junctions is shown in Fig. 2B. When diagrammed in this way, junctional homologies (underlined) occupy the same position in all three lines. The sequences of the nine BW330-26A deletion derivatives are shown in Fig. 3A. Eight 
A

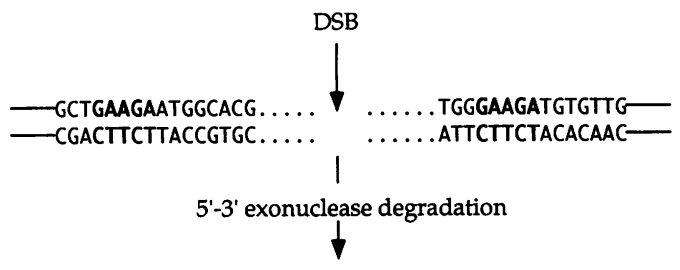

— GCTGAagaATGGCACG..... ......ATtCTTCTACACAAC-

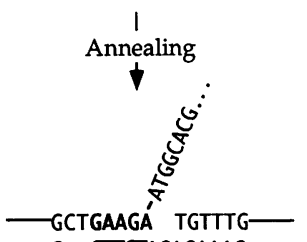

$\longrightarrow$ CTTCTACACAAAC -

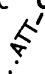

Excision of non-homologous sequences, ligation and resynthesis

$\downarrow$

- GCTGAAGA TGTGTTTG-

B

$$
\begin{aligned}
& \text { Proximal to the DSB GCTGAAGA ATGGCACG } \\
& \begin{array}{l}
\text { Junction } \\
\text { Distal to the DSB }
\end{array}
\end{aligned}
$$

FIG. 2. A model for strand annealing to create deletions between short homologies. (A) 5' to $3^{\prime}$ exonucleolytic degradation of the ends of a DSB exposes single-stranded regions of homology (GAAGA). After annealing of the partner strands, nonhomologous sequences are excised and gaps are filled in by DNA repair synthesis and ligation. (B) The convention used in Fig. 3 for representing deletion junctions is shown. Only the top strand ( $5^{\prime}$ to $\left.3^{\prime}\right)$ is shown; junctional nucleotide homologies are underlined.

of the nine deletion junctions contain one or more nucleotides of homology, although only two have 3 or more overlapping bp.

Deletions on a conditional dicentric chromosome. Nonspecific DSBs were generated in a conditional dicentric rad52 haploid, J178-\#7-20, as described elsewhere (4). A dicentric chromosome III was constructed by inserting GAL1::CEN3 at the HIS4 locus $45 \mathrm{~kb}$ to the left of the resident CEN3 (Fig. 4). This $C E N$ is under the control of an inducible $G A L 1$ promoter, so that transcription through the inserted CEN3 during growth in galactose medium inactivates it, allowing normal chromosome III segregation during mitosis $(4,21)$. In glucose medium, transcription from the $G A L 1$ promoter is repressed, resulting in a functionally dicentric chromosome. As has been previously observed, dicentric chromosomes in $S$. cerevisiae are mitotically unstable and prone to DNA rearrangements, often resulting in the loss of one of the centromeres $(4,19,21,22,62)$. Hence, the mitotic lethality could be rescued by deleting one of the centromere sequences. A total of $0.04 \%$ of cells survived growth on glucose, most of which contained centromere deletions that ranged from about $200 \mathrm{bp}$ to more than $4 \mathrm{~kb}$ (4). Deletions of either the conditional centromere or the normal CEN3 were recovered (Fig. 4), with the majority of events removing the conditional centromere. Approximately $13 \%$ of all deletions were contained within the 900-bp GAL1::CEN3 BamHI

\begin{tabular}{|c|c|c|c|c|c|}
\hline $\begin{array}{l}\text { deletion } \\
\text { strain }\end{array}$ & $\begin{array}{l}\text { deletion junction } \\
\text { sequence }\end{array}$ & $\begin{array}{l}\text { deletion } \\
\text { size }\end{array}$ & $\begin{array}{l}\text { deletion } \\
\text { strain }\end{array}$ & $\begin{array}{l}\text { deletion junction } \\
\text { sequence }\end{array}$ & $\begin{array}{l}\text { deletion } \\
\text { size }\end{array}$ \\
\hline BW-B13 & $\begin{array}{l}\text { CTGCTCGC TGAAGAAT } \\
\text { CTGCTCOC TGGIDGTG } \\
\text { ATAGAGTG TGGTCGIG }\end{array}$ & $173 \mathrm{bp}$ & $\mathrm{BW}-\mathrm{A} 3$ & $\begin{array}{l}\text { TACTTCTT TTAACCTT } \\
\text { TACTTCTT OCTATTTG } \\
\text { ATAQCTAT } \text { CLTATTTG }\end{array}$ & $653 \mathrm{bp}$ \\
\hline $\mathrm{BH}-\mathrm{B} 17$ & $\begin{array}{l}\text { ATGTTTCA AAACATTA } \\
\text { ATGTTTCA TATAGAGT } \\
\text { TTTGOCCT TATAGAGT }\end{array}$ & $689 \mathrm{bp}$ & BW-D2 & $\begin{array}{l}\text { GCTGAAGA ATGGCAOG } \\
\text { GCTGAAGA TGTGTTTG } \\
\text { TGGGAAGA TGTGTTTG }\end{array}$ & $138 \mathrm{bp}$ \\
\hline $\mathrm{BW}-\mathrm{F} 32$ & $\begin{array}{l}\text { GAGCATAT TACTCACA } \\
\text { GAGCATAT OCTATTTG } \\
\text { ATAQCTAT OCTATTTG }\end{array}$ & $282 \mathrm{bp}$ & $\mathrm{BW}-\mathrm{G} 30$ & $\begin{array}{l}\text { GICTTGIC TTCTCTGC } \\
\text { GTCTTGTC TGTACATT } \\
\text { TATGIGTT TGTACATT }\end{array}$ & $162 \mathrm{bp}$ \\
\hline BW-D11 & $\begin{array}{l}\text { CGGTGTAA AACAAAAT } \\
\text { CGGTGTAA CGGGACOG } \\
\text { TGGCTATA } ~ O B G G A C B G\end{array}$ & $485 \mathrm{bp}$ & BW-B28 & \begin{tabular}{|l} 
TCTCTOCT OGCTGAAG \\
TCTCTGCT AOCTIOGG \\
TECTAGTT AOCTTOGG
\end{tabular} & $575 \mathrm{bp}$ \\
\hline BW-A.5 & $\begin{array}{l}\text { AATGCAGC } \text { AOGGAATA } \\
\text { AATGCAOC } \$ G A G T G G T \\
\text { GGTTTTGT AGAGTGGT }\end{array}$ & $61 \mathrm{bp}$ & & & \\
\hline
\end{tabular}

$\mathbf{A}$

\begin{tabular}{|c|c|c|c|c|c|}
\hline $\begin{array}{l}\text { deletion } \\
\text { strain }\end{array}$ & $\begin{array}{l}\text { deletion function } \\
\text { sequence }\end{array}$ & $\begin{array}{l}\text { deletion } \\
\text { size }\end{array}$ & $\begin{array}{l}\text { deletion } \\
\text { strain }\end{array}$ & $\begin{array}{l}\text { deletion junction } \\
\text { sequence }\end{array}$ & $\begin{array}{l}\text { deletion } \\
\text { size }\end{array}$ \\
\hline $7-03$ & $\begin{array}{l}\text { TATACTTT AACGTCAA } \\
\text { TATACTTT AATGGTAT } \\
\text { TTICATTG AATGGIAT }\end{array}$ & $234 \mathrm{bp}$ & $4-2$ & $\begin{array}{l}\text { CCAAACAA TATGGAAA } \\
\text { CAAACAA TATTATTC } \\
\text { TCATATAT TATTATTC }\end{array}$ & $242 \mathrm{lp}$ \\
\hline 7-04 & $\begin{array}{l}\text { GTACAAAT AAGTCACA } \\
\text { GTACAAAT CAACTAAA } \\
\text { TGGTAAAG CAACTTAA }\end{array}$ & $233 \mathrm{sp}$ & 10 & $\begin{array}{l}\text { TAAAAGTA TCAACAAA } \\
\text { TAAAACTA TCATATAT } \\
\text { AGITTTCC TCATATAT }\end{array}$ & $305 \mathrm{bp}$ \\
\hline 7-06 & $\begin{array}{l}\text { TCTTATTC AAATGTAA } \\
\text { TCTTATTC AAAGAAA } \\
\text { GAAGAAT AAAGAAAA }\end{array}$ & 349 up & $2-6$ & $\begin{array}{l}\text { ACCTCTAT ACTTTAAC } \\
\text { ACCTCTAT ACTTAACA } \\
\text { GLAAACCA ACTTAACA }\end{array}$ & $325 \mathrm{bp}$ \\
\hline $7-19$ & $\begin{array}{l}\text { TTCTTATT CAAATGTA } \\
\text { TTCTTATT CAACTIAA } \\
\text { TGGTAAAG CAACTTAA }\end{array}$ & $369 \mathrm{dp}$ & $3-10$ & $\begin{array}{l}\text { ACTTTAAC TAATACTT } \\
\text { ACATTAAC TACTGGIG } \\
\text { GAAAOGTT TACTGGIG }\end{array}$ & $343 \mathrm{bp}$ \\
\hline $7-28$ & $\begin{array}{l}\text { CATAACCA CTTTAACT } \\
\text { CATAACCA CAATAGAA } \\
\text { TTATTATT CAATAGAA }\end{array}$ & $383 \mathrm{bp}$ & $1-3$ & $\begin{array}{l}\text { TAATTICTG GGGTAATT } \\
\text { TATTICTG AGGTAATG } \\
\text { CAGTAAAA AGGTAATG }\end{array}$ & $502 \mathrm{bp}$ \\
\hline $7-40$ & $\begin{array}{l}\text { CAAATTAA CAACCATA } \\
\text { CAAATTAA TTGAAAAA } \\
\text { GGIAATGA TTGAAAAA }\end{array}$ & $556 \mathrm{bp}$ & $3-8$ & $\begin{array}{l}\text { TGAAACGC AGATGTGC } \\
\text { TCAAACOC AGTTTIGC } \\
\text { CTGGTGGA AGTTTTCC }\end{array}$ & $602 \mathrm{bp}$ \\
\hline $\begin{array}{l}7-54 \\
7-59\end{array}$ & $\begin{array}{l}\text { ACAAAAAA TTGTTAAT } \\
\text { ACAAAAAA TTGGIAAA } \\
\text { AGAAAAAG TTGGTAAA }\end{array}$ & $332 \mathrm{bp}$ & $2-5$ & $\begin{array}{l}\text { GAACTTTC AGTAATAC } \\
\text { GACTTTC AGTAATPA } \\
\text { TCAATACA AGTAATAA }\end{array}$ & $760 \mathrm{bp}$ \\
\hline $7-64$ & $\begin{array}{l}\text { TTTCTATT ACTTCTTA } \\
\text { TTTCTATT ACAGTAAA } \\
\text { GCAACTTA ACAGTAAA }\end{array}$ & $295 \mathrm{bp}$ & $7-61$ & $\begin{array}{l}\text { AATATAOC TCTATACT } \\
\text { AATATACC TCAATAGA } \\
\text { ATTATTAT TCATAGA }\end{array}$ & $386 \mathrm{bp}$ \\
\hline
\end{tabular}

\begin{tabular}{|c|c|c|c|c|c|}
\hline $\begin{array}{l}\text { deletion } \\
\text { strain }\end{array}$ & $\begin{array}{l}\text { deletion junction } \\
\text { sequence }\end{array}$ & $\begin{array}{l}\text { deletion } \\
\text { size }\end{array}$ & $\begin{array}{l}\text { deletion } \\
\text { strain }\end{array}$ & $\begin{array}{l}\text { deletion junction } \\
\text { sequence }\end{array}$ & $\begin{array}{l}\text { deletion } \\
\text { size }\end{array}$ \\
\hline 603 & $\begin{array}{l}\text { GTATGAGA TCTAAATA } \\
\text { GLATGAGA OCAATAAT } \\
\text { GGGTIGA CGAATAAT }\end{array}$ & $117 \mathrm{bp}$ & 620 & $\begin{array}{l}\text { AATTTGTA GITCATAA } \\
\text { AATTTETA TGTACATT } \\
\text { GATGTGTT TGTACATT }\end{array}$ & $189 \mathrm{kp}$ \\
\hline 604 & $\begin{array}{l}\text { TTGGGTAT GIAATATG } \\
\text { TIGGGTAT AATTTIAT } \\
\text { AACAGTAT AATTTIAT }\end{array}$ & $146 \mathrm{kp}$ & 636 & $\begin{array}{l}\text { TATCCTAT ACTAACAA } \\
\text { TATCCTAT ATGIGTTT } \\
\text { TTGGGAAG ATGTGTTT }\end{array}$ & $195 \mathrm{lpp}$ \\
\hline 647 & 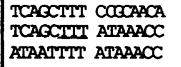 & $18 \mathrm{bp}$ & 642 & \begin{tabular}{|l} 
TCAATATC ACCOCAAG \\
TCAATATC ACATTTGG \\
GIGITTGT ACATTTGG
\end{tabular} & $360 \mathrm{lpp}$ \\
\hline 614 & \begin{tabular}{|l} 
TTGTAGTA TGGCGAAA \\
TTGTAGTA OGTGGTGA \\
CTGAAGTA $\cong G T G G T G A$
\end{tabular} & $596 \mathrm{lp}$ & 629 & $\begin{array}{l}\text { TCGGGTTT TTCTTTTA } \\
\text { TCGGGTTTT ATAAAOCC } \\
\text { ATAATTTT ATAАACOC }\end{array}$ & $37 \mathrm{bp}$ \\
\hline
\end{tabular}

FIG. 3. Sequences of deletion junctions. For each deletion junction presented, only top-strand sequences are shown. The top line represents the original sequence at the left side of the junction, the middle line represents the deletion junction itself, and the bottom line represents the original sequence at the right side of the junction (see Fig. 2). Nucleotide homologies present at the junction occupy the same position in all three lines and are underlined in the middle line. The site of the joint is represented by a space, although in cases in which homologies are present the nucleotides in question could have come from either side of the junction. Sequences of deletion derivatives from $M A T \alpha$ ho swil rad52 strain BW330-26A (A), from MATa GAL1::CEN3 rad52 strain J178-\#7-20 (B), and from MATa rad52 GAL::HO strain J178-20T (C) are shown. 


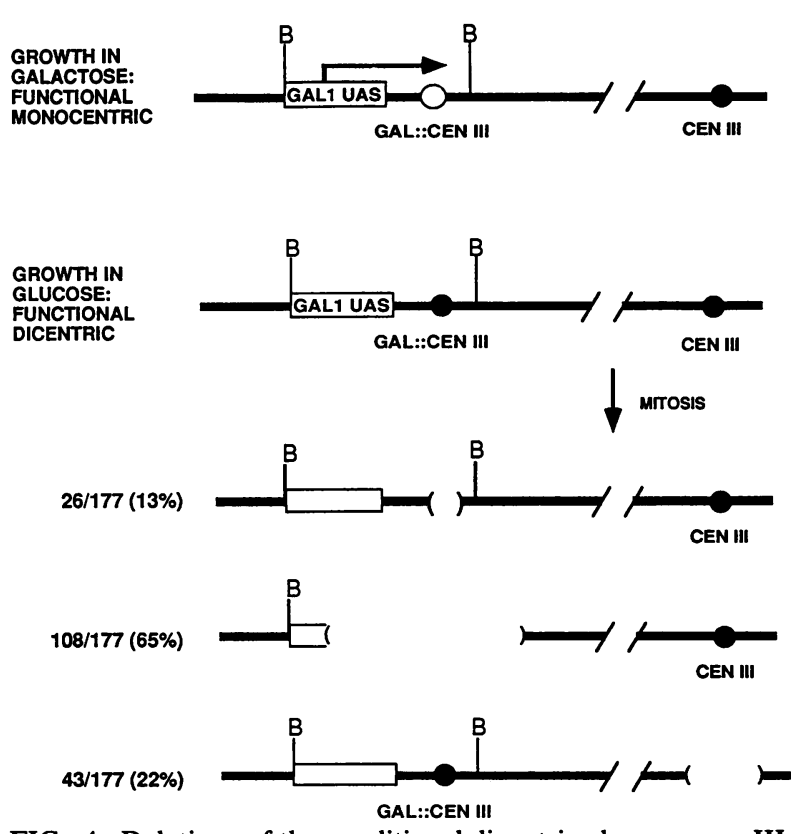

FIG. 4. Deletions of the conditional dicentric chromosome III in strain J178-\#7-20. Chromosome III carries a second CEN3 under control of a $G A L 1$ promoter inserted $45 \mathrm{~kb}$ from the resident copy of CEN3 (4). During mitotic growth in galactose-containing medium, the inserted $C E N 3$ is inactivated as a result of transcription from the $G A L$ promoter, yielding a functionally monocentric chromosome. During growth in glucose, transcription from the $G A L$ promoter is repressed, resulting in a functionally dicentric chromosome. Glucose medium is largely lethal to this strain, which lacks $R A D 52$ function because DSBs generated during mitotic growth cannot be repaired by homologous recombination. Cells can survive by deleting one of the CEN3 sequences. The frequencies of deletions that removed one or the other $C E N 3$ are indicated. We have analyzed strains in which deletions of the inserted $C E N 3$ are confined within the BamHI (B) fragment.

fragment (Fig. 4), of which we have examined 17. As before, the region of interest was PCR amplified and sequenced. The sizes of these deletions ranged from 233 to $760 \mathrm{bp}$, with a mean size of $343 \mathrm{bp}$ (Fig. 1B). We note that these deletions represent a selected subset that retain the proximal Bam $\mathrm{HI}$ site and that many other deletions were substantially larger.

During mitotic segregation of the dicentric chromosome, the DSB presumably occurred between the two CEN3 sequences (Fig. 4) and therefore to the right of the CDEIII element of the inserted $C E N 3$. Although a deletion of only a few nucleotides of CDEIII would be sufficient to eliminate centromere function $(5,15,39,57)$, all of these deletions removed all three of the CDE elements constituting a yeast centromere (Fig. 1B). Thus, as with the HO-induced deletions, far more sequences are removed than are required to overcome lethality by eliminating centromere function. Under the assumption that the DSB occurred in the $160 \mathrm{bp}$ between the CEN3 CDEIII element and the right-hand BamHI site, it appears that in most cases, more sequences were deleted to the left of the break site than to the right (Fig. 1B). However, by restricting our analysis to deletions contained within the BamHI GAL1::CEN3 fragment, we may have selected events in which the deletion was asymmetric around the break site.

The results of PCR amplification and DNA sequencing of the CEN3 deletion junctions are presented in Fig. 3B, with nucleotide homologies underlined as described above. Of 17

\begin{tabular}{|c|c|c|}
\hline Wild type $M A T$ a & GCTTTCOSCAACA GIATAATTT & \multirow[b]{2}{*}{ number of examples } \\
\hline \multirow{2}{*}{ Deletions } & & \\
\hline & GCTTTCCGC $\mathrm{A}_{\mathrm{A}} \mathrm{ACAGIATAATTT}$ & 1 \\
\hline \multicolumn{3}{|l|}{ Insertions } \\
\hline & GCTTTCCGCAACA ${ }^{\text {CA }}$ GTATAATTT & 6 \\
\hline & GCTTTCCGCAACA ${ }^{\text {ACA }}$ GTATAATTT & 2 \\
\hline
\end{tabular}

FIG. 5. Small duplicative insertions and a single-base pair deletion recovered in the GAL1::HO MATa rad52 strain J178-20T. The 4-bp 3' overlapping ends of the HO cleavage site are underlined in the wild-type sequence. The deletion of a single base pair is indicated by the boldface subscripted base. The duplications of 2 or $3 \mathrm{bp}$ at the $\mathrm{HO}$ cutting site are indicated by boldface superscripted letters.

deletion events, all but 2 had junctional homologies ranging from 1 to at least 7 nucleotides. The other two (7-04 and 1-3) had, respectively, 3 and 6 nucleotides of homology offset from the junctions by $1 \mathrm{bp}$.

Deletions in GAL::HO strains. The deletions created by HO endonuclease were generated in a strain background different from that used to analyze the survivors of dicentric chromosome breakage. Therefore, we undertook another experiment to compare the two types of deletion events in the same genetic background. We used a monocentric rad52 haploid J178-20T strain isogenic to dicentric J178-\#7-20 but carrying a plasmid-borne $\mathrm{HO}$ gene under the control of a $G A L$ promoter $(8,24)$. Growth on galactose medium in the monocentric strain is almost always lethal, since the HO cut at $M A T$ cannot be repaired by homologous recombination in a rad52 background. Deletions around the HO cut site were isolated by plating cells on galactose-containing medium and by analyzing the survivors. In several experiments, the frequency with which survivors appeared was $1 \times 10^{-4}$ to $4 \times 10^{-4}$. Deletions around the HO cutting site will leave strains either MATa or matal, depending on the size of the deletion. These two types can be distinguished by mating them to MAT $\alpha$ tester strains, as described in Materials and Methods. A combination of Southern analysis and DNA sequence analysis (see below) of 50 galactose-insensitive survivors has revealed that they can be grouped into four classes. The distribution of deletion sizes in J178-20T MATa rad52 GAL::HO derivatives is as follows (numbers are the numbers that were analyzed): for 1- to 3-bp deletions and small insertions, $36(72 \%)$; 20 - to 100 -bp deletions, $9(18 \%)$; 100 -bp to $1-\mathrm{kb}$ deletions, $4(8 \%)$; >1-kb deletions, $1(2 \%)$. Deletions of approximately $20 \mathrm{bp}$ or larger could be resolved on Southern blots of StyI-digested genomic DNA probed with a $M A T$ distal-specific probe (61).

We have determined the deletion end points of eight randomly selected deletions that were detectable by Southern blot analysis (greater than approximately $20 \mathrm{bp}$ ) (Fig. $1 C)$. They have an average size of $207 \mathrm{bp}$ and have the same degree of shared homology at their junctions as did the centromere deletions made in the same strain background or the HO-induced deletions in a different background (Fig. $3 C)$.

The majority of survivors (72\%) make up a new class of small deletion or insertion events not observed in the $H O$ swil rad52 strain. We have PCR amplified and sequenced nine of the junctions of these events. As shown in Fig. 5, all of these deletions and insertions involved the $4 \mathrm{bp}$ that are the site of the staggered $3^{\prime}$ overhanging cuts on the two 


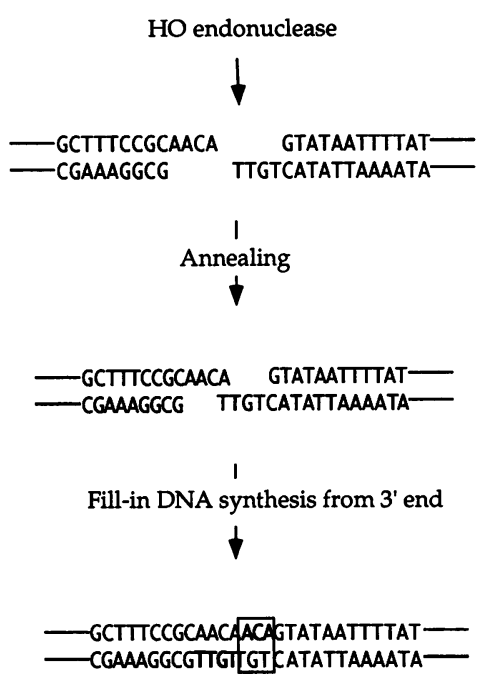

FIG. 6. Possible mechanism to create small duplications of the MAT a cutting site. The terminal bases at the $3^{\prime}$ ends of the HO cleavage site can anneal and permit primer extension from the $3^{\prime}$ ends to fill in the bases missing in the gap and create a 3-bp (ACA) insertion. If the terminal $3^{\prime} T$ of the lower strand is removed, the annealing of the adjacent $T$ followed by primer extension will create a 2-bp insertion (CA). Deletion of several nucleotides from both ends and annealing can also give rise to the 1-bp deletion (606) seen in Fig. 5.

strands of the HO recognition site. One was a deletion of a single base pair; the others were insertions of 2 or $3 \mathrm{bp}$. These types of duplication events can best be explained by an annealing of complementary bases near the $3^{\prime}$ overhanging single-stranded ends, after which the $3^{\prime}$ end may be used as a primer to fill in the missing bases (Fig. 6). Such events have been well documented in vertebrate cells and in in vitro studies $(25,42,49,65)$.

\section{DISCUSSION}

We have examined the process of illegitimate recombination in $S$. cerevisiae resulting from a DSB generated in vivo by studying deletion events in recombination-deficient strains. On the basis of sequence analysis of the deletion junctions, we conclude that nucleotide homologies play a significant role in the end joining of the partner DNA molecules; 39 of 43 events had 1 to at least $7 \mathrm{bp}$ of homology at the junctions. The presence of very short regions of DNA sequence identity at the end points of the deletions is statistically significant; this can be seen by calculating the random probability that any deletion event would contain $X$ nucleotides of homology at a given junction, with unbiased base composition, based on the formula $P(X)=(X+$ $1)(1 / 4)^{X}(3 / 4)^{2}(48)$. This formula applies only to nucleotides exactly at the junction; therefore, for the purposes of this calculation, events such as the dicentric derivatives 7-04 and 1-3 are considered to have no junctional nucleotide homologies, even though homologies around the junction may have had a role in the end-joining event, as discussed below. The comparison between the number of expected and observed homologies, shown in Fig. 7, revealed that there are significantly more events with 2 or more nucleotides of homology than would be expected by random occurrence. This suggests that these homologies play a significant role in the joining of the DNA ends, possibly by an annealing event

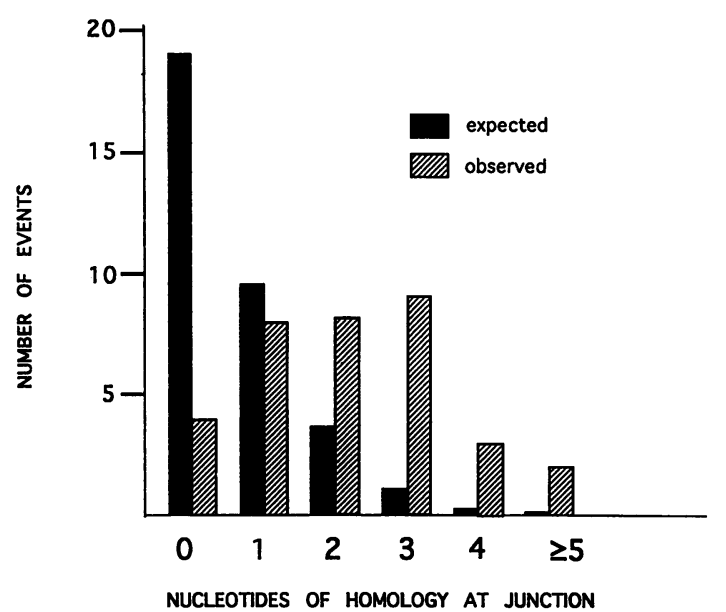

FIG. 7. Expected versus observed junctional homologies. The probability of finding $\mathrm{X}$ nucleotides of homology at the junction of a deletion was calculated by using the formula $P(X)=(X+1)$ $(1 / 4)^{X}(3 / 4)^{2}$ assuming unbiased base composition (48). The expected numbers are represented by black bars. The observed numbers (based on the 34 examples in Fig. 3) are represented by striped bars.

which stabilizes the partner molecules, allowing ligation. This small but significant number of homologous nucleotides at the junctions of deletions has also been found in mammalian cells (48).

We point out that in some cases, notably in the dicentric derivatives 7-54 and 7-59 (Fig. 3B), the homology at the deletion junction is discontinuous. Thus, we have assigned only 3 nucleotides of homology to those junctions, even though there is a total of 11 potential base pairings with two single-nucleotide interruptions. Three other events (7-04 and 1-3 [Fig. 3B] and 620 [Fig. 3C]) had 3 and 6 nucleotides of homology offset by $1 \mathrm{bp}$ at the junction which may have participated in the end-joining event. Schiestl et al. (53) have reported similar observations in the insertion of nonhomologous DNA into $S$. cerevisiae and have suggested that such cases may have necessitated mismatch repair of the heteroduplex DNA which is an efficient process in $S$. cerevisiae $(41,44)$. The idea that longer, discontinuous regions of homology may help align sequences that are to be joined is also suggested from the homologous recombination studies described by Mézard et al. (33).

How, then, does RAD52-independent deletion repair of a DSB occur? Our previous studies have shown that the creation of a DSB by $\mathrm{HO}$ endonuclease is followed by extensive $5^{\prime}$ to $3^{\prime}$ exonuclease DNA degradation $(14,59,61$, 68 ) resulting in the formation of long $3^{\prime}$-ended single strands. In $\mathrm{Rad}^{+}$cells, such DSB can be repaired very efficiently by SSA between flanking homologous regions that can be as short as 30 to $60 \mathrm{bp}(59,60)$. In rad52 cells, SSA is also possible, but only at much lower efficiency or when the flanking homologous regions are very long, as in rDNA repeats $(14,38,43)$. In our present work, we find that at efficiencies of between 0.05 and $1 \%$, single strands may also anneal in the absence of $R A D 52$ function. Here, there are but a few bases of complementary sequence that might act to stabilize the partner DNA molecules long enough to permit any necessary excision of nonhomologous sequences and complete ligation (Fig. 2). It is unclear whether the similarities between $R A D 52$-dependent annealing of longer homologous regions and these $R A D 52$-independent junctions of as 
few as 1 bp of homology are a reflection of some common processes or whether they represent truly independent pathways. Recently, we have shown that a UV repair gene, $R A D 1$, plays a crucial role in the removal of nonhomologous DNA from the $3^{\prime}$ ends of HO-cut molecules undergoing $\mathrm{Rad}^{+}$SSA and deletion formation (13). It will be interesting to determine whether the RAD52-independent deletion events that we have documented here also require $R A D 1$. $R A D 1$ is not needed for integration of linear transformed DNA by illegitimate recombination (56).

An inspection of the current data also argues that there are several different pathways for nonhomologous recombination in $S$. cerevisiae. All of the systems used to study illegitimate recombination in $S$. cerevisiae have shown that most events were mediated through base pairing of at least a few nucleotides. However, both the integration of linear transformed nonhomologous DNA $(53,55,56)$ and recombination between highly diverged genes of common function (33) have proven to be $R A D 52$ dependent, even though the junctions of recombination involve only a few base pairs. It is possible that the HO-induced deletion-repair events that we have studied also occur more frequently in RAD52 cells; however, this is unlikely. The most compelling evidence that this type of deletion repair does not occur much more frequently in $\mathrm{Rad}^{+}$cells comes from studies of HO-induced attempts to switch the mating type in cells from which the two homologous donor sequences, $H M L$ and $H M R$, are deleted (26). In these studies, cells that suffer a DSB at $M A T$ must either repair the break by nonhomologous means or die. Essentially, all cells died. Survivors, which arose at no more than a few percent, had generated base substitutions or small deletions at the HO cut site such as those reported here. This is similar to our results with rad52 cells unable to complete recombination (66) and in $\mathrm{Rad}^{+}$strains that lacked mating-type donors (69).

We have found at least 1 , and perhaps 4 , of 43 deletions that appear to have resulted from blunt-end ligation when there was no homology at the junction. Such events have also been seen when nonhomologous transforming DNA integrates at sites that are likely to have been cleaved by topoisomerase I (53). It is unclear whether these events arise by still another pathway of repair. Ligation involving no homology can occur by two blunt-ended molecules coming together or by a blunt end and a $5^{\prime}$ protruding end coming together followed by $5^{\prime}-3^{\prime}$ repair synthesis filling in of the 5 overhang and ligation, as described elsewhere for mammalian cells (49).

The majority of the events that we have analyzed can be accounted for by the kind of process illustrated in Fig. 2. Studies of higher eucaryotic as well as in bacterial systems have reported deletions flanked by small direct repeats $(7$, $25,28,40,47,64)$. It has been estimated that roughly $60 \%$ of mammalian end-joining events involve short regions of nucleotide homology (49), including junctions of spontaneous deletions as well as those resulting from end joining of transformed or transfected DNA molecules (47). These types of events also occur in vitro in the presence of Xenopus egg cell extracts (65) and in human cell extracts (64). Taken together, these data suggest that there is a common nonhomologous deletion repair process that is similar in a wide variety of organisms ranging from bacteria to yeasts to mammals. Moreover, we have shown that the same kinds of events occur after DSBs are created in two quite different ways, one by a site-specific enzymatic cleavage and the other by mechanical rupture of DNA.

An unusual feature of the deletions of CEN3. The deletions described here are generally much larger than those that would be required to relieve lethality. In strains in which the deletion resulted from an $\mathrm{HO}$ cut, removal of a single base pair could have overcome the lethal condition. This is also the case in the monocentric derivatives of the dicentric strain. Because the events that we analyzed preserved a $B a m H I$ site 160 bp to the right of $C E N 3$, the initial rupture of the dicentric chromosome presumably occurred in that interval (Fig. 4). CEN3 itself consists of a 125 -bp sequence which can be subdivided into three elements: CDEI, CDEII, and CDEIII $(5,9,39)$. Removal of CDEI plus parts of CDEII diminishes the quality of chromosome transmission significantly but does not abolish it. Removal of CDEIII totally abolishes CEN activity (39). Additionally, CDEIII is the only element in which single-base pair mutations have been shown to abolish CEN function $(23,32)$. In fact, a dicentric plasmid containing one normal CEN3 and another with a mutation in CDEIII does not exhibit dicentric behavior (27). In our experiments, CEN3 is oriented so that the DSB should arise between CDEIII and the right-hand BamHI site (Fig. 4). Surprisingly, although removal of only CDEIII should suffice, every deletion removed the entire centromere region (Fig. 1B). This suggests that the entire CEN3 must be removed before an end-joining event can occur. $C E N$ sequences are known to interact with protein components in a nuclease-resistant complex $(3,52)$. Perhaps the DNA ends within the $C E N$ sequences are unavailable to participate in end joining because of their interactions with proteins, and only when sequences outside CEN3 are uncovered can the deletion event occur. An alternative interpretation is that the breakage of dicentric chromosomes does not occur by simple mechanical rupture of DNA but is mediated by nucleases that cleave the stretched chromatin fiber, perhaps on both sides of the centromere.

Another type of DSB repair: creation of small duplications at the $\mathrm{HO}$ cleavage site. When $M A T$ deletions were generated in a strain carrying a $G A L:: H O$ plasmid, the majority of galactose survivors belonged to a new class of insertion events (Fig. 5). These events were not seen when deletions of $M A T$ were selected in the $H O$ swil-1 rad52 strain. There are two possible explanations for this difference, both related to the expression of $\mathrm{HO}$ endonuclease from a galactose-regulated promoter. The first is that the galactoseinduced $\mathrm{HO}$ gene is expressed in all phases of the cell cycle and in both mother and daughter cells, while the normal HO gene is tightly regulated and confined to the end of the $G_{1}$ phase of the cell cycle in mother cells $(8,24,34)$. Possibly, the repair of HO-induced DSBs occurs by different pathways at different points in the cell cycle. Alternatively, the level of HO endonuclease may influence the repair process. Compared with normal HO gene expression, $G A L:: H O$ levels appear to be 100 -fold higher. However, this is somewhat misleading, in that the gene is expressed in both mothers and daughters and throughout the cell cycle, instead of being confined to perhaps 10 to $20 \%$ of the cell cycle in mother cells. Thus, the level of HO endonuclease induced by galactose may be only 5 to 10 times what is normally present. The relative level of HO expression may be even lower in HO swil-1 cells; however, it has not been established whether the swil-1 mutation permits a low level of expression in most cells or a normal level of HO transcription in a few cells. It should be noted that even in galactose-induced cells, $28 \%$ of the survivors contain deletions that are virtually identical to those obtained in the $H O$ swil-1 cells.

We believe that the mechanism for forming small duplications of nucleotides in the HO cleavage site is best explained 
by the annealing and filling-in mechanism diagrammed in Fig. 6. This type of mechanism has been studied extensively in vertebrate cells by Pfeiffer and her colleagues $(42,65)$. Possibly, when $\mathrm{HO}$ endonuclease is present at higher levels, it helps hold the two ends of the cleaved DNA in proximity so that the offset base pairing can occur. However, it is difficult to see how HO endonuclease could remain bound while the small gaps in the annealed sequence were being filled in by a repair DNA polymerase. These considerations lead us to suspect that these novel duplication insertions arise by repair at a time in the cell cycle when $\mathrm{HO}$ is not normally expressed.

Deletions between very short homologous regions are rare in $S$. cerevisiae. In $S$. cerevisiae, the process of homologous recombination is so efficient that until recently it has been difficult to analyze illegitimate recombination. One might expect to see such events among spontaneous mutations, especially after ionizing radiation treatments, but in fact spontaneous deletions in $S$. cerevisiae are rare $(11,12)$. There is one interesting exception to the lack of deletions among spontaneous events. The telomere-associated $Y^{\prime}$ element of $S$. cerevisiae exist in two forms $\left(\mathrm{Y}^{\prime}\right.$ long and $\mathrm{Y}^{\prime}$ short) that differ from each other in about $1 \%$ of their nucleotide sequences (30). The size difference between the two forms arises from 11 small deletions, each of which appears to have arisen by recombination between flanking regions of 4 to $10 \mathrm{bp}$. $\mathrm{Y}^{\prime}$ elements are also unusual in that they are not found in many other members of the genus Saccharomyces and have some resemblance to viral elements (30). This may suggest that the deletions arose as a consequence of some unusual feature of the replication of these elements.

In summary, we have shown that two very different types of DSBs-one by a site-specific endonuclease cleavage and the other by mechanical breakage of DNA - are repaired by a similar mechanism in the absence of the recombination gene $R A D 52$. The types of deletions that we described are reminiscent of analogous events described in many organisms, ranging from bacterial cells to higher eucaryotes $(6,25$, $47,65)$. The ability to analyze the genetic control of these events in yeasts, as we have done for HO-induced homologous recombination events $(14,59)$, should make it possible to determine what gene products are required for illegitimate recombination.

\section{ACKNOWLEDGMENTS}

Wai-Ying Leung generously helped with PCR amplifications and DNA sequencing of some $G A L:: H O$-induced deletions.

This work was supported by grant GM32238 from the National Institutes of Health to K.B. and by Department of Energy grant no. DE-G05-91ER61235 to J.E.H. K.K. was supported by a National Institutes of Health Genetics training grant, GM07122.

\section{REFERENCES}

1. Ahn, B.-Y., K. J. Dornfeld, T. J. Fagrelius, and D. M. Livingston. 1988. Effect of limited homology on gene conversion in a Saccharomyces cerevisiae plasmid recombination system. Mol. Cell. Biol. 8:2442-2448.

2. Arnheim, N., and H. Erlich. 1992. Polymerase chain reaction strategy. Annu. Rev. Biochem. 61:131-156.

3. Bloom, K., and J. Carbon. 1982. Yeast centromere DNA is in a unique and highly ordered structure in chromosomes and small circular minichromosomes. Cell 29:305-317.

4. Brock, J., and K. Bloom. Cell cycle regulation of centromere function in Saccharomyces cerevisiae. In B. Vig and M. Resnick (ed.), Chromosome segregation and aneuploidy. NATO workshop, in press. Springer-Verlag, New York.
5. Carbon, J. 1984. Yeast centromeres: structure and function. Cell 37:351-353.

6. Conley, E. C., V. A. Saunders, V. Jackson, and J. R. Saunders. 1986. Mechanism of intramolecular recyclization and deletion formation following transformation of Escherichia coli with linearized plasmid DNA. Nucleic Acids Res. 14:8919-8932.

7. Conley, E. C., V. A. Saunders, and J. R. Saunders. 1986. Deletion and rearrangement of plasmid DNA during transformation of Escherichia coli with linear plasmid molecules. Nucleic Acids Res. 14:8905-8918.

8. Connolly, B., C. I. White, and J. E. Haber. 1988. Physical monitoring of mating type switching in Saccharomyces cerevisiae. Mol. Cell. Biol. 8:2342-2349.

9. Cottarel, G., J. H. Shero, P. Hieter, and J. H. Hegemann. 1989. A 125-base-pair CEN6 DNA fragment is sufficient for complete meiotic and mitotic centromere functions in Saccharomyces cerevisiae. Mol. Cell. Biol. 9:3342-3349.

10. Deng, C., and M. R. Capecchi. 1992. Reexamination of gene targeting frequency as a function of the extent of homology between the targeting vector and the target locus. Mol. Cell. Biol. 12:3365-3371.

11. Ernst, J. F., J. W. Stewart, and F. Sherman. 1981. The cyc1-11 mutation in yeast reverts by recombination with a nonallelic gene: composite genes determining the isocytochrome-c. Proc. Natl. Acad. Sci. USA 78:6334-6338.

12. Fink, G. R., and C. A. Styles. 1974. Deletion mutants in yeast. Genetics 77:231-244.

13. Fishman-Lobell, J., and J. E. Haber. 1992. Removal of nonhomologous DNA ends in double-strand break recombination: the role of the yeast ultraviolet repair gene $R A D 1$. Science 258:480 484.

14. Fishman-Lobell, J., N. Rudin, and J. E. Haber. 1992. Two alternative pathways of double-strand break repair that are kinetically separable and independently modulated. Mol. Cell. Biol. 12:1292-1303.

15. Fitzgerald-Hayes, M., L. Clarke, and J. Carbon. 1982. Nucleotide sequence comparisons and functional analysis of yeast centromere DNAs. Cell 29:235-244.

16. Haber, J. E. 1992. Exploring the pathways of homologous recombination. Curr. Opin. Cell Biol. 4:401-412.

17. Haber, J. E. 1992. Mating-type gene switching in Saccharomyces cerevisiae. Trends Genet. 8:446-452.

18. Haber, J. E., and B. Garvik. 1977. A new gene affecting the efficiency of mating type interconversions in homothallic strains of Saccharomyces cerevisiae. Genetics 87:33-50.

19. Haber, J. E., and P. C. Thornburn. 1984. Healing of broken linear dicentric chromosomes in yeast. Genetics 106:207-226.

20. Herskowitz, I. 1989. A regulatory hierarchy for cell specialization in yeast. Nature (London) 342:749-757.

21. Hill, A., and K. Bloom. 1989. Acquisition and processing of a conditional dicentric chromosome in Saccharomyces cerevisiae. Mol. Cell. Biol. 9:1368-1370.

22. Jager, D., and P. Philippsen. 1989. Stabilization of dicentric chromosomes in Saccharomyces cerevisiae by telomere addition to broken ends or by centromere deletion. EMBO J. 8:247-254.

23. Jehn, B., R. Niedenthal, and J. H. Hegemann. 1991. In vivo analysis of the Saccharomyces cerevisiae centromere CDEIII sequence: requirements for mitotic chromosome segregation. Mol. Cell. Biol. 11:5212-5221.

24. Jensen, R., and I. Herskowitz. 1984. Directionality and regulation of cassette substitution in yeast. Cold Spring Harbor Symp. Quant. Biol. 49:97-104.

25. King, J. S., E. R. Valcarcel, J. T. Rufer, J. W. Phillips, and W. F. Morgan. 1993. Noncomplementary DNA double-strandbreak rejoining in bacterial and human cells. Nucleic Acids Res. 21:1055-1059.

26. Klar, A. J. S., J. N. Strathern, and J. A. Abraham. 1984. Involvement of double-strand chromosomal breaks for matingtype switching in Saccharomyces cerevisiae. Cold Spring Harbor Symp. Quant. Biol. 49:77-88.

27. Koshland, D., L. Rutledge, M. Fitzgerald-Hayes, and L. H. Hartwell. 1987. A genetic analysis of dicentric minichromo- 
somes in Saccharomyces cerevisiae. Cell 48:801-812.

28. Krawczak, M., and D. N. Cooper. 1991. Gene deletions causing human genetic disease: mechanisms of mutagenesis and the role of the local DNA sequence environment. Hum. Genet. 86:425441.

29. Kunes, S., D. Botstein, and M. S. Fox. 1984. Formation of inverted dimer plasmids after transformation of yeast with linearized plasmid DNA. Cold Spring Harbor Symp. Quant. Biol. 49:617-628.

30. Louis, E. J., and J. E. Haber. 1992. The structure and evolution of subtelomeric $\mathrm{Y}^{\prime}$ elements in Saccharomyces cerevisiae. Genetics 131:559-574.

31. Malone, R. E., and R. E. Esposito. 1980. The RAD52 gene is required for homothallic interconversion of mating types and spontaneous mitotic recombination in yeast. Proc. Natl. Acad. Sci. USA 77:503-507.

32. McGrew, J., B. Diehl, and M. Fitzgerald-Hayes. 1986. Single base-pair mutations in centromere element III cause aberrant chromosome segregation in Saccharomyces cerevisiae. Mol. Cell. Biol. 6:530-538.

33. Mézard, C., D. Pompon, and A. Nicolas. 1992. Recombination between similar but not identical DNA sequences during yeast transformation occurs within short stretches of identity. Cell 70:659-670.

34. Nasmyth, K. 1983. Molecular analysis of a cell lineage. Nature (London) 302:670-676.

35. Nasmyth, K. 1987. The determination of mother cell-specific mating type switching in yeast by a specific regulator of $\mathrm{HO}$ transcription. EMBO J. 6:243-248.

36. Nickoloff, J. A., J. D. Singer, M. F. Hoekstra, and F. Heffron. 1989. Double-strand breaks stimulate alternative mechanisms of recombination repair. J. Mol. Biol. 207:527-541.

37. Orr-Weaver, T., J. W. Szostak, and R. J. Rothstein. 1981. Yeast transformation: a model system for the study of recombination. Proc. Natl. Acad. Sci. USA 78:6351-6358.

38. Ozenberger, B. A., and G. S. Roeder. 1991. A unique pathway of double-strand break repair operates in tandemly repeated genes. Mol. Cell. Biol. 11:1222-1231.

39. Panzeri, L., L. Landonio, A. Stotz, and P. Philippsen. 1985. Role of conserved sequence elements in yeast centromere DNA. EMBO J. 4:1867-1874.

40. Pastink, A., C. Vreeken, A. P. Schalet, and J. C. J. Eeken. 1988. DNA sequence analysis of $\mathrm{X}$-ray-induced deletions at the white locus of Drosophila melanogaster. Mutat. Res. 207:23-28.

41. Petes, T. D., R. E. Malone, and L. S. Symington. 1991. Recombination in yeast, p. 407-521. In E. W. Jones, and J. R. Pringle (ed.), the molecular and cellular biology of the yeast Saccharomyces. Cold Spring Harbor Laboratory, Cold Spring Harbor, N.Y.

42. Pfeiffer, P., and W. Vielmetter. 1988. Joining of nonhomologous DNA double strand breaks in vitro. Nucleic Acids Res. 16:907924.

43. Plessis, A., A. Perrin, J. E. Haber, and B. Dujon. 1992. Sitespecific recombination determined by I-SceI, a mitochondrial group $I$ intron-encoded endonuclease expressed in the yeast nucleus. Genetics 130:451-460.

44. Ray, B. L., C. W. White, and J. E. Haber. 1991. Heteroduplex formation and mismatch repair of the "stuck" mutation during mating-type switching in Saccharomyces cerevisiae. Mol. Cell. Biol. 11:5372-5380.

45. Resnick, M. A., and P. Martin. 1976. The repair of doublestrand breaks in the nuclear DNA of Saccharomyces cerevisiae and its genetic control. Mol. Gen. Genet. 143:119-129.

46. Roeder, G. S., and S. E. Stewart. 1988. Mitotic recombination in yeast. Trends Genet. 4:263-267.

47. Roth, D., and J. Wilson. 1988. Illegitimate recombination in mammalian cells, p. 621-653. In R. Kucherlapati and G. R. Smith (ed.), Genetic recombination. American Society for $\mathrm{Mi}$ crobiology, Washington, D.C.

48. Roth, D. B., T. N. Porter, and J. H. Wilson. 1985. Mechanisms of nonhomologous recombination in mammalian cells. Mol. Cell. Biol. 5:2599-2607.

49. Roth, D. B., and J. H. Wilson. 1986. Nonhomologous recombination in mammalian cells: role of short sequence homologies in the joining reaction. Mol. Cell. Biol. 6:4295-4304.

50. Rudin, N., and J. E. Haber. 1988. Efficient repair of HO-induced chromosomal breaks in Saccharomyces cerevisiae by recombination between flanking homologous sequences. Mol. Cell. Biol. 8:3918-3928.

51. Saiki, R. K., D. H. Gelfand, S. Stoffel, S. J. Scharf, R. Higuchi, G. T. Horn, K. B. Mullis, and H. A. Erlich. 1988. Primerdirected enzymatic amplification of DNA with a thermostable DNA polymerase. Science 239:487-491.

52. Saunders, M., M. Fitzgerald-Hayes, and K. Bloom. 1988. Chromatin structure of altered yeast centromeres. Proc. Natl. Acad. Sci. USA 85:175-179.

53. Schiestl, R. H., M. Dominska, and T. D. Petes. 1993. Transformation of Saccharomyces cerevisiae with nonhomologous DNA: illegitimate integration of transforming DNA into yeast chromosomes and in vivo ligation of transforming DNA to mitochondrial DNA sequences. Mol. Cell. Biol. 13:2697-2705.

54. Schiestl, R. H., and R. D. Gietz. 1989. High efficiency transformation of intact yeast cells using single stranded nucleic acids as carrier. Curr. Genet. 16:337-346.

55. Schiestl, R. H., and T. D. Petes. 1991. Integration of DNA fragments by illegitimate recombination in Saccharomyces cerevisiae. Proc. Natl. Acad. Sci. USA 88:7585-7589.

56. Schiestl, R. H., and T. D. Petes. 1992. Illegitimate recombination in yeast, p. S286. 16th Int. Conf. Yeast Genet. Mol. Biol., San Francisco. John Wiley \& Sons, Ltd., New York.

57. Schulman, I. G., and K. Bloom. 1993. Genetic dissection of centromere function. Mol. Cell. Biol. 13:3156-3166.

58. Sherman, F., G. R. Fink, and J. B. Hicks. 1983. Methods in yeast genetics. Cold Spring Harbor Laboratory, Cold Spring Harbor, N.Y.

59. Sugawara, N., and J. E. Haber. 1992. Characterization of double-strand break-induced recombination: homology requirements and single-stranded DNA formation. Mol. Cell. Biol. 12:563-575.

60. Sugawara, N., and J. E. Haber. Unpublished results.

61. Sun, H., D. Treco, and J. W. Szostak. 1991. Extensive 3'overhanging, single-stranded DNA associated with the meiosisspecific double-strand breaks at the $A R G 4$ recombination initiation site. Cell 64:1155-1161.

62. Surosky, R. T., and B. K. Tye. 1985. Resolution of dicentric chromosomes by Ty-mediated recombination in yeast. Genetics 110:397-419.

63. Szostak, J. W., T. L. Orr-Weaver, R. J. Rothstein, and F. W. Stahl. 1983. The double-strand-break repair model for recombination. Cell 33:25-35.

64. Thacker, J., J. Chalk, A. Ganesh, and P. North. 1992. A mechanism for deletion formation in DNA by human cell extracts: the involvement of short sequence repeats. Nucleic Acids Res. 20:6183-6188.

65. Thode, S., A. Schafer, P. Pfeiffer, and W. Vielmetter. 1990. A novel pathway of DNA end-to-end joining. Cell 60:921-928.

66. Weiffenbach, B., and J. E. Haber. 1981. Homothallic mating type switching generates lethal chromosome breaks in rad52 strains of Saccharomyces cerevisiae. Mol. Cell. Biol. 1:522534.

67. Weiffenbach, B., D. T. Rogers, J. E. Haber, M. Zoller, D. W. Russell, and M. Smith. 1983. Deletions and single base pair changes in the yeast mating type locus that prevent homothallic mating type conversions. Proc. Natl. Acad. Sci. USA 30:34013405 .

68. White, C. I., and J. E. Haber. 1990. Intermediates of recombination during mating type switching in Saccharomyces cerevisiae. EMBO J. 9:663-673.

69. Wu, X., K. Kramer, and J. E. Haber. Unpublished results. 